\title{
Prevalence of Intestinal Parasites in Dogs from Municipality La Lisa, Havana, Cuba
}

\author{
Luis Enrique Jerez Puebla*1, Fidel A. Nunez ${ }^{1}$, Lazara Rojas Rivero ${ }^{1}$, Yordan Robau Hernandez ${ }^{2}$, Ismaris Suarez Garcia ${ }^{2}$ and Irais Atencio Millan ${ }^{1}$ \\ ${ }^{1}$ Department of Parasitology, Tropical Medicine Institute, Pedro Kourí, Autopista Novia del Mediodia, Autopista Nacionaly Carretera Central, La Habana, Cuba \\ ${ }^{2}$ Canine Veterinary Unit, La Lisa, La Habana, Cuba
}

*Corresponding author: Luis Enrique Jerez Puebla, Department of Parasitology, Tropical Medicine Institute, Pedro Kourí, Autopista Novia del Mediodía, Autopista Nacional y Carretera Central, La Habana, Cuba, Tel: 537-255-3645; E-mail: luis.jerez@vetsuisse.unibe.ch; luisjerezpuebla@infomed.sld.cu

Rec date: Jul 25, 2015; Acc date: Aug 18, 2015; Pub date: Aug 20, 2015

Copyright: $\odot 2015$ Puebla LEJ, et al. This is an open-access article distributed under the terms of the Creative Commons Attribution License, which permits unrestricted use, distribution, and reproduction in any medium, provided the original author and source are credited.

\begin{abstract}
Intestinal parasitic infections in dogs represent a major concern in developing countries as they are important definitive or reservoir hosts for several zoonotic parasites. The present study was conducted to determine the prevalence of intestinal parasitic infections in stray dogs and domestic dogs in the municipality of la Lisa, in La Havana, between June 2014 to March 2015. A total of 97 faecal samples from 56 stray dogs and 41 household dogs were examined by parasitological concentration techniques. The overall prevalence of gastrointestinal parasites was 44.3\% (95\% Cl: 33.9-54.7). Ancylostoma caninum (21.6\%), Trichuris vulpis (16.5) and Giardia duodenlis (7.2\%) were the most prevalent intestinal parasites identified in canine faecal samples, indicating an important faecal contamination of the analyzed area. There were no significant differences between the prevalence of gastrointestinal parasites and the kind of dog analyzed. However stray dogs were associated with a higher risk of infection as well as those older than 1 year old. This information may be useful in the implementation of effective prevention and control programmes by the National Group of Zoonosis in our country. Appropriate public health education for dog's owners is necessary to reduce the risks of zoonotic infections.
\end{abstract}

Keywords: Intestinal parasites; Stray dog; Domestic dog; Prevalence; Risk factors; Havana

\section{Introduction}

Intestinal parasitic infections in dogs are commonly recognized as a cause of gastrointestinal disorders with a high prevalence in developing countries [1]. Among intestinal helminthes of dogs, Toxocara canis represents the major concern as it can cause severe infection in humans [2].Other zoonotic helminths like Ancylostoma caninum and $A$. braziliensi are primary causes of cutaneous, visceral, and ocular larva migrans and eosinophilic enteritis [3].

Environmental fecal contamination by infected dogs represents a source of infection for humans. In fact, parasitic elements, like eggs, larvae, cysts, and oocysts excreted via canine fecal route can survive over a long time and be infective in the environment at different condition [4]. For that reason is necessary to make epidemiological studies to obtain data from dogs which can undoubtedly contribute to preventing direct zoonotic transmission from dogs to humans via the control of infectious animals [4].

In Cuba there are approximately 2 million of dogs, almost one per habitant, and half of this canine population are stray dogs according to data of the Ministry of Cuban Health, from which 200000 resides in the capital of our country [5]. The municipality of La Lisa with an extension of 37.5 square kilometers, in La Havana, has a Canine Veterinary Unit which receives stray and domestic dogs for analysis and veterinary control.

In Cuba, there are few reports regarding that important issue. The last one identified Toxocara canis and Dipylidium caninum as the most prevalent in one surveillance study in La Habana [5]. Given the lack of current knowledge about the prevalence of intestinal parasites in canine population, we aimed in this study to identify the prevalence of intestinal helminths among stray and domestic dogs in the municipality La Lisa, in Havana, Cuba.

\section{Material and Methods}

\section{Study area and dogs}

A descriptive cross-sectional study was carried out from conducted from June 2014 to March 2015 in a population of dogs attending at the Veterinary Unit from the municipality of La Lisa, province of La Habana, Cuba. Using a prevalence of infections $10 \%$, a total sample size of 97 out of 8371 of total dogs of this area was calculated for $90 \%$ confidence level.

A standard questionnaire was used to collect information regarding individual features (age, sex, breed, and presence/absence of clinical signs) and management (indoor/outdoor housing) by clinicians. The samples for this study were chosen at random on various days, and collected by veterinarians as part of veterinary health checks and were derived from 56 stray dogs and 41 household dogs.

The research protocol was approved by the Ethics Committee of the "Pedro Kourí" Institute.

\section{Coproparasitological study}

Faecal samples were taken directly from rectums (in accordance with animal welfare guidelines) or from the ground immediately after defecation by veterinary personnel and placed in one collector containing a $2.5 \%$ potassium dichromate solution. First, macroscopic examination was performed for the detection of proglottids of 
Page 2 of 3

cestodes. The faecal sample was transferred to test tubes and washed three times with distilled water (800xg for three minutes) to remove potassium dichromate. A sample of about $2 \mathrm{~g}$ was processed for intestinal parasites by a wet smear stained with Lugol's iodine and followed by formalin ethyl acetate concentration technique. All samples were processed also by the Kato-Katz smear method and the flotation technique of Willy-Malloy for the identification of parasite eggs. To all diarrheal faecal samples a stained by modified acid-fast for Cryptosporidium spp., Cyclospora, and Cystoisospora was done [6].

\section{Statistical Analysis}

All data were analysed using EPINFO 6.04 and EPIDAT 3.1 statistical programmes. Chi square test and proportion tests were employed to assess the significance of the associations.

The odds ratio (OR) with $95 \%$ confidence interval (CI) were performed as measures of association. The association between potential risk factors and intestinal parasitic infections was assessed by the Chi-square test with a $95 \%$ confidence interval. The $\mathrm{P}$ values less than 0.05 were considered as statistically significant for all test.

\section{Results}

Out of 97 dogs studied, 43 (44.3\%) were infected with both either zoonotic or non-zoonotic parasites. The zoonotic parasites Ancylostoma caninum (21.6\%), and Trichuris vulpis (16.5\%), and the protozoan parasite, Giardia duodenalis $(7.2 \%)$ were the more prevalent. Mixed infections were detected in 11 faecal sample $(11.34 \%$, 95\% $\mathrm{CI}=4.5-18.2$ ).

Among the kind of dog investigated, stray dogs had more frequency of infection due to Ancylostoma caninum (15/56, 26.8\%) and Trichuris vulpis $(11 / 56,19.6 \%)$, whereas $G$. duodenalis was more prevalent in domestic dogs $(4 / 41,9.8 \%)$ (Table 1$)$.

\begin{tabular}{|c|c|c|c|c|}
\hline \multirow[t]{2}{*}{ Parasite } & \multirow{2}{*}{$\begin{array}{l}\text { Household dogs ( } n=41) \\
n \text { (\% infected) }\end{array}$} & \multirow{2}{*}{$\begin{array}{l}\text { Stray dogs }(n=56) \\
n(\% \text { infected) }\end{array}$} & \multicolumn{2}{|l|}{ Total $(n=97)$} \\
\hline & & & $\mathbf{n}(\%$ infected $)$ & $(95 \% \mathrm{Cl})$ \\
\hline Ancylostoma caninum & $6(14.6)$ & $15(26.8)$ & $21(21.6)$ & $12.94-30.36$ \\
\hline Trichuris vulpis & $5(12.2)$ & $11(19.6)$ & $16(16.5)$ & $8.59-24.4$ \\
\hline Giardia duodenalis & $4(9.8)$ & $3(5.4)$ & $7(7.2)$ & $1.55-12.88$ \\
\hline Toxocara canis & $0(0)$ & $3(5.4)$ & $3(3.1)$ & $0.64-8.77$ \\
\hline Strongyloides stercoralis & $0(0)$ & $2(3.6)$ & $2(2.1)$ & $0.25-7.25$ \\
\hline Blastocystis spp. & $1(2.4)$ & $1(1.8)$ & $2(2.1)$ & $0.25-7.25$ \\
\hline Isospora canis & $1(2.4)$ & $1(1.8)$ & $2(2.1)$ & $0.25-7.25$ \\
\hline Physaloptera praeputidae & $0(0)$ & $1(1.8)$ & $1(1.0)$ & $0.03-5.61$ \\
\hline
\end{tabular}

Table 1: Distribution of intestinal parasites of medical importance identified in dog faecal samples by concentration techniques.

\begin{tabular}{|c|c|c|c|c|c|c|}
\hline Risk Factor & Total & Infected (\%) & OR & $95 \% \mathrm{Cl}$ & $P$ value & $\mathrm{X}^{2}$ test \\
\hline \multicolumn{7}{|l|}{ Age } \\
\hline $\begin{array}{l}\text { Puppy } \\
\text { months })\end{array} \quad(<12$ & 28 & $8(28.6)$ & & & & \\
\hline $\begin{array}{lll}\begin{array}{l}\text { Adult } \\
\text { months) }\end{array} & (> & 12 \\
\end{array}$ & 69 & $35(50.7)$ & 2.57 & $\begin{array}{l}0.99- \\
6.63\end{array}$ & $0.04^{*}$ & 3.96 \\
\hline \multicolumn{7}{|l|}{ Gender } \\
\hline Male & 37 & $13(35.1)$ & & & & \\
\hline Female & 60 & $30(50.0)$ & 1.85 & $0.79-4.29$ & 0.15 & 2.05 \\
\hline \multicolumn{7}{|l|}{ Housing } \\
\hline Stray & 56 & $32(57.1)$ & 3.64 & $1.52-8.68$ & $0.003^{*}$ & 8.81 \\
\hline Household & 41 & $11(26.9)$ & & & & \\
\hline
\end{tabular}

Table 2: Univariate analysis of risk factors for intestinal parasites in dogs attending at the Veterinary Unit from La Lisa, Habana, Cuba.

In order to associate some epidemiological variables with the risk of infection by intestinal parasites in the dogs studied, some factors were analyzed including age (puppy or adult), gender (male or female), ownership status (stray, or domestic). Univariate analysis identified that stray dogs and adult's one were significant risk factors associated with intestinal parasites infection as is shown in Table 2.

\section{Discussion}

It is known throughout the history of domestication that dogs have played and act a pivotal role as definitive hosts or reservoirs for different zoonotic parasites, especially in developing countries [7], and due to the close and frequent contact between dogs and people the risk for the transmission of zoonotic diseases is considered high [8].

In this study, there were no statistical differences between the infecting parasite and the group of dog studied, indicating an important faecal contamination in the analyzed area, as indicates the prevalence of the soil-transmitted helminths, Ancylostoma caninum and Trichuris vulpis. Almost 15\% of household dogs were infected by A. caninum, which means a potential risk for their owners to be in contact with the infective stages of canine hookworms, and lead to the development of cutaneous larva migrans and eosinophilic enteritis [9]. Hookworm pathogenesis in dogs is related to their capability of causing anaemia, and in puppies the disease caused by large numbers of Ancylostoma caninum are often fatal [10]. 
Although the prevalence of Toxocara canis was low, around 3\%, this nematode is recognized as one of the most prevalent in the canine population worldwide causing in humans ocular toxocariosis and visceral larva migrans zoonotic diseases [11].

Giardia arose as the third more prevalent intestinal parasite in our study. In fact, according to some authors In fact, Giardia is currently the most common cause of parasitic disease in domestic dogs and cats $[12,13]$. We found a higher prevalence of Giardia in household dogs, being important from the epidemiological point of view due to the potential zoonotic of this parasite. Currently, the zoonotic transmission of $G$. duodenalis has gained more evidence, particularly the role of dogs which can harbour either zoonotic or host specific assemblages of Giardia [14].

The present study on prevalence rates of intestinal parasites in dogs from one municipality of La Havana, is slightly different from that made by Hernández et al., [5] where they identified Ancylostoma spp. (21\%), Dipylidium caninum (16.3\%) and Toxocara canis $(19.7 \%)$ as the most frequent helminths in a higher number of dogs [5]. Nonetheless, worlwide reports show that Ancylostoma, Toxocara, Trichuris, and Dipilidium are the most frequent helminths identified in dogs $[12,13]$.

Several studies addressing the epidemiology of gastrointestinal parasites in dogs have been conducted in urban areas worldwide. Demographics, geographic location, seasonal trends, and husbandry, have all been considered as risk factors for parasitism [15,16]. We identified in this study that stray dogs and adult's one have had a higher risk of acquire a parasitic infection. That could be explained by the fact that stray or abandoned animals do not receive attention by their owner and in most cases rarely or never received antiparasitic treatments. Therefore, they have a higher probability of be infected by intestinal parasites and develop also a pronounce symptomatology compared to household [17].

According to the Zoonosis Department of Cuba, there are almost 1 million of stray dogs nowadays around the country, and some policies are conducted to face this subject [18]. That's why veterinary care and public health education need to be increased in order to protect the dogs, their owners. The present results on prevalence of intestinal parasites found in household dogs might indicate that veterinary control in canine population is not strength enough.

In conclusion, we found that dogs in the municipality of La Lisa, were infected with zoonotic and non-zoonotic species of intestinal parasites. The most prevalent parasites identified were Ancylostoma caninum, Trichuris vulpis and Giardia duodenalis. It is necessary then to both, control of stray dogs and appropriate public health education for dog's owners to reduce the risks of zoonotic infections and follow up with epidemiological studies in different areas of the country.

\section{Competing Interests}

The authors declare that they have no competing interests.

\section{Acknowledgements}

We would like to thank the members of the Veterinary Unit of la Lisa for all the support in this investigation.

\section{References}

1. David ÉB, Guimarães S, de Oliveira AP, Goulart de Oliveira-Sequeira TC, Nogueira Bittencourt G, et al. (2015) Molecular characterization of intestinal protozoa in two poor communities in the State of São Paulo, Brazil. Parasit Vectors 8: 103.

2. Nijsse R, Ploeger HW, Wagenaar JA, Mughini-Gras L (2015) Toxocara canis in household dogs: prevalence, risk factors and owners' attitude towards deworming. Parasitol Res 114: 561-569.

3. McKenzie E, Riehl J, Banse H, Kass PH, Nelson S Jr, et al. (2010) Prevalence of diarrhea and enteropathogens in racing sled dogs. J Vet Intern Med 24: 97-103.

4. Lee AC, Schantz PM, Kazacos KR, Montgomery SP, Bowman DD (2010) Epidemiologic and zoonotic aspects of ascarid infections in dogs and cats. Trends Parasitol 26: 155-161.

5. Hernández Merlo R, Fidel Núñez A, Pelayo Durán L (2007) [Zoonotic potential of intestinal helminth infections in stray dogs from City of Havana]. Rev Cubana Med Trop 59: 234-240.

6. Garcia LS (2001) Intestinal protoazoa coccidia and microspordia In: Garcia L (ed) Diagnostic Medical Parasitology (4thedn) American Society of Microbiology, Washington.

7. Salb AL, Barkema HW, Elkin BT, Thompson RC, Whiteside DP, et al. (2008) Dogs as sources and sentinels of parasites in humans and wildlife, northern Canada. Emerg Infect Dis 14: 60-63.

8. Klimpel S, Heukelbach J, Pothmann D, Rückert S (2010) Gastrointestinal and ectoparasites from urban stray dogs in Fortaleza (Brazil): high infection risk for humans? Parasitol Res 107: 713-719.

9. Landmann JK, Prociv P (2003) Experimental human infection with the dog hookworm, Ancylostoma caninum. Med J Aust 178: 69-71.

10. Liu Y1, Zheng G, Alsarakibi M, Zhang X, Hu W, et al. (2014) The zoonotic risk of Ancylostoma ceylanicum isolated from stray dogs and cats in Guangzhou, South China. Biomed Res Int 2014: 208759.

11. Robertson ID, Thompson RC (2002) Enteric parasitic zoonoses of domesticated dogs and cats. Microbes Infect 4: 867-873.

12. Palmer CS, Thompson RC, Traub RJ, Rees R, Robertson ID (2008) National study of the gastrointestinal parasites of dogs and cats in Australia. Vet Parasitol 151: 181-190.

13. Gates MC, Nolan TJ (2014) Declines in canine endoparasite prevalence associated with the introduction of commercial heartworm and flea preventatives from 1984 to 2007. Vet Parasitol 204: 265-268.

14. Traub RJ, Monis PT, Robertson I, Irwin P, Mencke N, et al. (2004) Epidemiological and molecular evidence supports the zoonotic transmission of Giardia among humans and dogs living in the same community. Parasitology 128: 253-262.

15. Gaunt MC, Carr AP (2011) A survey of intestinal parasites in dogs from Saskatoon, Saskatchewan. Can Vet J 52: 497-500.

16. Wang A, Ruch-Gallie R, Scorza V, Lin P, Lappin MR (2012) Prevalence of Giardia and Cryptosporidium species in dog park attending dogs compared to non-dog park attending dogs in one region of Colorado. Vet Parasitol 184: 335-340.

17. Becker AC, Rohen M, Epe C, Schnieder T (2012) Prevalence of endoparasites in stray and fostered dogs and cats in Northern Germany. Parasitol Res 111: 849-857.

18. Ministerio de Salud Pública de Cuba (2005) Informe departamento de zoonosis. La Habana:MINSAP. 